\title{
NEW RECORDS OF BASIDIOMYCETES FROM THE PSKOV REGION IN THE POLISTOVSKIY STATE NATURE RESERVE (RUSSIA)
}

\author{
Lyudmila B. Kalinina ${ }^{1, *}$, Sergey Yu. Bolshakov ${ }^{1}$, Tatiana M. Bulyonkova ${ }^{2}$ \\ ${ }^{1}$ Komarov Botanical Institute of RAS, Russia \\ ${ }^{2}$ Ershov Institute of Informatics Systems, SB RAS, Russia \\ *e-mail:lkalinina@binran.ru
}

Received: 07.02.2020. Revised: 29.04.2020. Accepted: 30.04.2020.

\begin{abstract}
Prior to a present paper, 918 species of basidiomycete fungi were known in the Pskov region (Russia), including 512 species recorded in the Sebezhskiy National Park. Fungal inventorying studies in Protected Areas are an important part of biodiversity assessment. The constantly expanding knowledge on this vast group of organisms, powered by new finds in the field and advances in molecular genetics, make fungal inventorying in any territory a long-term effort rather than an isolated event. In 2019, we assessed the fungal biota of the Polistovskiy State Nature Reserve (Pskov region, Russia) in various forest types in the core and buffer zones along nine designated routes. The material was studied using the standard methods of fungal taxonomy. As a result, 74 basidomycete species new to Pskov region were revealed. Among them, six species (Galerina hybrida, Gymnopus erythropus, Lepiota boudieri, Pluteus velutinus, Rugosomyces obscurissimus, and Simocybe haustellaris) were new to the Northwest of European Russia and four species (Achroomyces effusus, Botryobasidium stigmatisporum, Galerina caulocystidiata, and Pseudobaeospora celluloderma) were new for Russia. The former are here provided with brief notes, whereas the latter are supplied with descriptions of studied specimens, drawings of microstructures and discussion of their distribution, habitats, similar and closely related species, and current state of knowledge. We found also Hemistropahria albocrenulata, a protected species in Finland and the adjacent Leningrad region and Novgorod region. Helicogloea compressa was registered for the second time in Russia, with another record in St. Petersburg city. Despite substantially expanding our knowledge of the mycobiota in both the Polistovskiy State Nature Reserve and Pskov region, the present data are still insufficient for a comprehensive quantitative analysis of its structure.
\end{abstract}

Key words: Achroomyces effusus, Botryobasidium stigmatisporum, Galerina caulocystidiata, Northwest of European Russia, Polistovo-Lovat' bog system, Pseudobaeospora celluloderma

\section{Introduction}

Fungi play an essential role as decomposers of dead matter as well as mycorrhizal symbionts of plants. Fungi inventory studies are a keystone for further investigations. The knowledge of biodiversity in Protected Areas (PAs) allows us to detect indicator species, assess species rarity under undisturbed conditions, reveal community structures and to investigate more complex processes and phenomena. Fungi of PAs are the object of study in several countries (e.g. Lisiewska \& Tortić, 1990; Roberts, 1999; Friedrich, 2002; Lacheva \& Radoukova, 2014; Kunttu et al., 2015; Bolshakov \& Volobuev, 2016; Telleria et al., 2016; Brandrud et al., 2019; Erofeeva et al., 2019), sometimes with an emphasis on rare and threatened species (e.g. Adamčík et al., 2007a; Karasiński et al., 2009; Langer et al., 2014; Holec et al., 2015) or on various analyses of the revealed mycobiota (e.g. Iršènaite et al., 2013; Baird et al., 2014; Gogoi \& Parkash, 2015; Holec et al., 2015; Aučina et al., 2019).

As a comprehensive review of literature dealing with fungi in Russian PAs is beyond the scope of the present paper, we only point out that basidio- mycetes in Protected Areas in northwestern Russia and adjacent territories are studied quite well. The studies dealing with fungi inventory have been carried out in Nizhne-Svirsky State Nature Reserve, Leningrad region (Zmitrovich et al., 2015), Central-Forest State Nature Reserve, Tver region (Kotkova, 2014), Valdaiskiy National Park, Novgorod region (Popov et al., 2013), and in Belorussian Braslav Lakes National Park and Narochanskiy National Park (Popov et al., 2013).

Until the present study, 918 basidiomycete species were known in the whole Pskov region (Kotkova \& Popov, 2013; Popov et al., 2013; Bolshakov et al., 2019). The studies focused primarily on the Sebezhskiy National Park with 512 species revealed (Kovalenko et al., 2003; Kotkova \& Popov, 2012; Popov et al., 2013). Until now, there were no other published data on fungi in the Polistovskiy State Nature Reserve (PSNR).

The study, performed in the PSNR, was aimed to reveal basidiomycete species new to Pskov region by pursuing the following tasks: 1) to perform an inventory of basidiomycetes in various vegetation types in PSNR; 2) to identify collected 
specimens; 3) to compare the list of the discovered species with extant data and to reveal new taxa; 4) to compile a list of basidiomycete species new to Pskov region and possibly to higher administrative territories; 5) to describe the studied specimens of species new to Russia; 6) to perform a preliminary analysis of the obtained data.

\section{Study area}

\section{Material and Methods}

Pskov region is the easternmost administrative region in the northwest of European Russia (Leningrad region, Pskov region, and Novgorod region according to Sennikov, 2005). This area lies between $55.6166^{\circ}-59.0166^{\circ} \mathrm{N}$ and $27.3500^{\circ}$ $31.5000^{\circ} \mathrm{E}$, spanning $380 \mathrm{~km}$ from north to south and $202 \mathrm{~km}$ from west to east, forming a somewhat stretched shape along the NW-SE axis (Fig. 1). The area is located within the northwestern part of the Eastern European platform. It includes uplands in its northern, central and southern parts as well as lowlands in the west and the east of the region.

The PSNR is situated in the eastern part of the Pskov region (Fig. 1). It was established in
1994 to protect the western part of PolistovoLovat' bog system, the eastern part of which is protected by the Rdeisky State Nature Reserve (Novgorod region). This area is mostly covered with raised bogs in different development stages (Bogdanovskaya-Guiheneuf, 1969). Several mineral islands with various vegetation types are located in the bog. There are some temperate broadleaf stands with Quercus robur L., Tilia cordata Mill., and Alnus glutinosa (L.) Gaertn. in the southeastern part of the PA. In the northern part of the PSNR, there are some old-growth coniferous forests with Pinus sylvestris L. and Picea abies (L.) H. Karst. (Galanina, 2005). Bog margins are dominated by deciduous forests with Betula spp. and Populus tremula L., secondary to coniferous stands. Sorbus aucuparia $\mathrm{L}$. is common in the undergrowth.

The field investigations were performed by the classical route method (or opportunistic sampling according to Lodge et al., 2004) during an inventory study of agaricoid fungi in various types of forest vegetation in the core and buffer zones of the PSNR. The routes are denoted as follows.

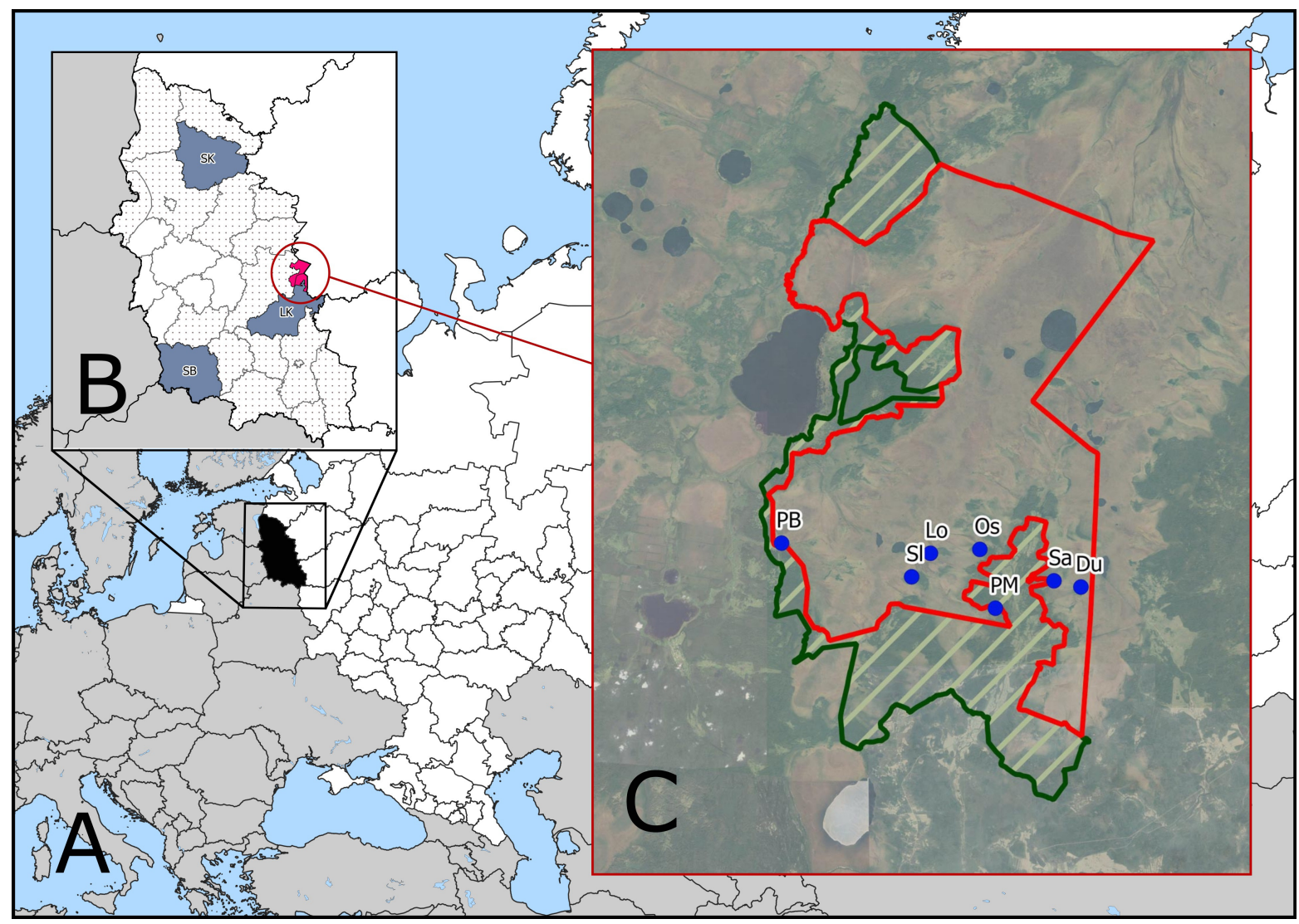

Fig. 1. A - Pskov region (in black) on the map of Russia. B - Pskov region. The richness of basidiomycete species registered in the administrative districts of the Pskov region: white - no species registered, dotted - 1 to 50 species, blue - over 50 species (LK Loknyanskiy district, SB - Sebezhskiy district, SK - Strugokrasnenskiy district). Location of Polistovskiy State Nature Reserve is marked by red. C - the routes in the Polistovskiy State Nature Reserve (PM - trail «Put' Mokhovikov» («Bolete Path»), Du - mineral island «Dubovets», PB - trail «Plavnitskoe Boloto» («Plavnitsk Wetland»), Sl-mineral island «Slepetnoe», Os - stow «Osinovik», $\mathrm{Sa}-$ stow «Sapozhok», Lo - mineral island «Maloe Loshye»). The core zone of the PA is outlined in red. The buffer zone is hatched. 
Trail «Put' Mokhovikov» («Bolete Path»). The trail runs through the southeastern part of the PSNR with abandoned villages and farmlands. Secondary forests with Betula spp. and Populus tremula are the most common along the path. But there are also abundant mixed stands (Picea abies, Quercus robur, Tilia cordata) and a stretch of transitional bog with Betula spp.

Mineral island «Dubovets». The island is covered with wet mixed Populus tremula and Picea abies forest.

Trail «Plavnitskoe Boloto» («Plavnitsk Wetland»). The trail crosses various types of wetlands (marshes, fens, and bogs) as well as secondary Betula-Populus forest, Picea abies and Populus tremula, Alnus glutinosa forest, a secondary postagricultural meadow, and a small mineral island covered by mixed stands (Picea abies, Pinus sylvestris, Populus tremula). This is the most iconic trail of the PSNR.

Mineral island «Slepetnoe». The vegetation types of the mineral island are very diverse. They include Alnus glutinosa forests, mixed Picea-Betula stands with Tilia cordata and Sorbus aucuparia in the undergrowth, and small areas with mixed Quercus-Tilia stands.

Stow «Osinovik». The margin of the bog extending to the west is covered by old-growth Populus tremula forest with scattered old Picea abies trees and undergrowth consisting of Alnus glutinosa and abundant young Quercus robur.

Stow «Sapozhok». Bog margin protruding and tapering from west to east into a massive raised bog. The western part is covered by secondary Populus tremula forest with a significant proportion of Quercus robur (both young and mature). Mixed Picea abies forest with Alnus glutinosa in the undergrowth covers the narrowing eastern part.

Mineral island «Maloe Loshye». The vegetation of the island consists of mixed stands (Picea abies, Populus tremula, Quercus robur, Tilia cordata).

\section{Data sampling}

The specimens were collected in the PSNR in 2019. Samples were studied according to classical methods of fungal taxonomy (Ivoilov et al., 2017). The taxonomy of species is presented generally according to Funga Nordica (Knudsen \& Vesterholt, 2012). The nomenclature of taxa follows the Index Fungorum (http://www.indexfungorum.org/). Macroscopic features of sporocarps were assessed in the field or shortly after collection. Microscopic structures were observed using Zeiss Axio Imager A1 and Zeiss AxioLab A1 microscopes in squash preparations mounted in $\mathrm{KOH}, 10 \%$ Congo Red in $\mathrm{NH}_{4} \mathrm{OH}$, Melzer's reagent and Cotton Blue. Drawings of microstructures were made using InkScape from microphotographs taken with AxioCam MRc5 and AxioVision Microscopy software. All specimens were determined by the authors except for Achroomyces effusus (J. Schröt.) Mig., identified by Vera F. Malysheva. The studied material is deposited in the Komarov Botanical Institute of RAS Mycological Herbarium (LE).

\section{Results}

Below is the list of species found in the PSNR and considered as new to the Pskov region. Each record contains data on the collection location, including administrative district, co-ordinates, and protection status of the site (core or buffer zone), vegetation type, substrate, date of collection, and herbarium number. An asterisk (*) indicates species found for the first time in the northwest of European Russia. An exclamation mark (!) is used for species new to Russia; besides these names are in bold. They are provided with a description of the studied specimens and drawings of microscopic structures.

! Achroomyces effusus (J. Schröt.) Mig. - Bezhanitskiy district, trail «Plavnitskoe boloto», core zone, $57.10167^{\circ} \mathrm{N}, 30.39167^{\circ} \mathrm{E}$, border of Sphagnum bog and mixed forest (Populus tremula, Picea abies), on rotten deciduous wood, 06.09.2019, LE 321787.

Corticioid heterobasidiomycete (Platygloeales, Pucciniomycetes) with resupinate gelatinous basidiomata, is characterised by clavate probasidia (Fig. 2b) and straight transversely septate metabasidia (Wojewoda, 1977; Hansen \& Knudsen, 1997). Mature metabasidia are 4-celled, with lateral sterigmata (Fig. 2c). Spores are crescent to broadly ellipsoid, germinating, hyaline, 5.7$7.1 \times 3.0-3.6 \mu \mathrm{m}$ (Fig. 2a).

Arrhenia epichysium (Pers.) Redhead, Lutzoni, Moncalvo \& Vilgalys - Loknyanskiy district, stow Osinovik, core zone, $57.09861^{\circ} \mathrm{N}, 30.58056^{\circ} \mathrm{E}$, Populus tremula forest with Picea abies and Quercus robur in undergrowth, on trunk of Populus tremula, 13.09.2019, LE 321788.

Arrhenia sphagnicola (Berk.) Redhead, Lutzoni, Moncalvo \& Vilgalys - Loknyanskiy district, stow Sapozhok, core zone, 57.08194 N, $30.65917^{\circ}$ E, Sphagnum bog, in Sphagnum, 09.09.2019, LE 321789. 
Boletus reticulatus Schaeff. - Loknyanskiy district, stow Maloe Loshye, core zone, $57.09722^{\circ} \mathrm{N}, 30.53056^{\circ} \mathrm{E}$, coniferous forest with Populus tremula and Betula sp., Tilia cordata, Sorbus aucuparia, Quercus robur in undergrowth, on soil, 02.09.2019, LE 321790.

! Botryobasidium stigmatisporum Boidin \& Gilles. - Loknyanskiy district, trail «Put' mokhovikov», buffer zone, $57.07194^{\circ} \mathrm{N}, 30.60639^{\circ} \mathrm{E}$, Alnus glutinosa forest, on rotten hardwood, 11.09.2019, LE 321791.

It is a corticioid species with ornamented spores. Hyphae are without clamps, basal hyphae thick-walled, very broad, 7-16 $\mu \mathrm{m}$, rarely up to $21 \mu \mathrm{m}$ (Fig. 3d). Basidia are 9.1$13.8 \times 6.3-7.2 \mu \mathrm{m}, 6-8$-spored (Fig. 3b,c). Spores are $4.3-5.5 \times 2.8-3.2 \mu \mathrm{m}$, thin-walled, minutely asperulate (in FC or DIC microscopy), ellipsoid (Fig. 3a). In our specimen, the spores are narrower than those in the original description (Boidin \& Gilles, 1988).

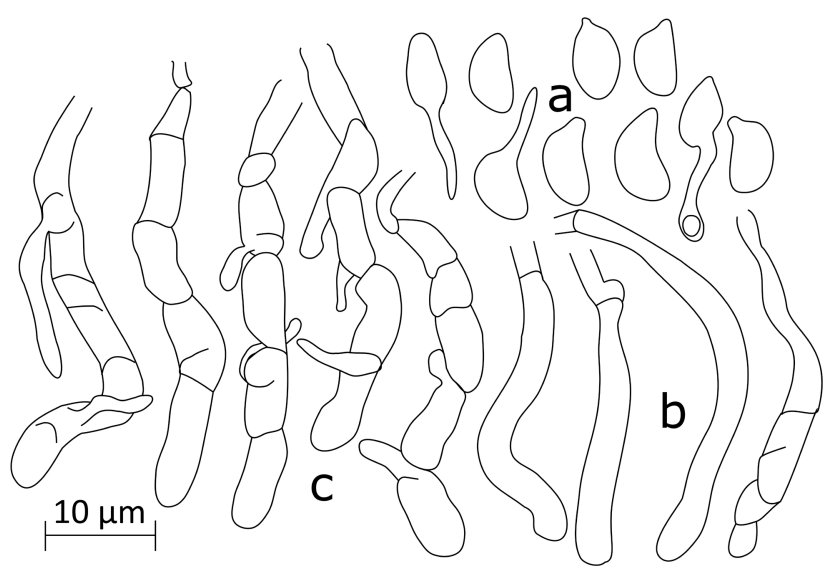

Fig. 2. Microscopic characteristics of Achroomyces effusus, LE 321787; a - basidiospores, b - probasidia, c - metabasidia.

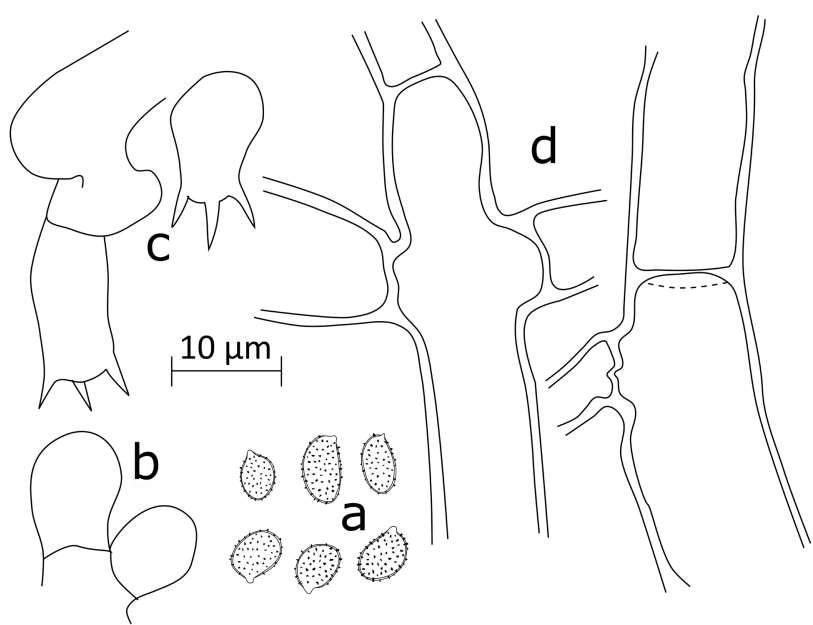

Fig. 3. Microscopic characteristics of Botryobasidium stigmatisporum LE 321791; a - basidiospores, b - young basidia, c mature basidia (only three sterigmata shown), d- basal hyphae.
Calyptella capula (Holmsk.) Quél. Loknyanskiy district, stow Sapozhok, core zone, $57.08292^{\circ} \mathrm{N}, 30.64311^{\circ} \mathrm{E}$, mixed Picea abies and Populus tremula forest, on herbaceous remnants, 09.09.2019, LE 321792.

Cheimonophyllum candidissimum (Sacc.) Singer - Loknyanskiy district, stow Dubovets, core zone, $57.07944^{\circ} \mathrm{N}, 30.67000^{\circ} \mathrm{E}$, secondary Betula-Populus forest, on trunk of Populus tremula, 09.09.2019, LE 321793.

Clavulinopsis luteoalba (Rea) Corner Loknyanskiy district, stow Osinovik, core zone, $57.09861^{\circ} \mathrm{N}, 30.57611^{\circ} \mathrm{E}$, coniferous forest with Quercus robur in undergrowth, on soil, 13.09.2019, LE 321795; stow Slepetnoe, core zone, $57.08361^{\circ} \mathrm{N}, 30.50611^{\circ} \mathrm{E}$, Quercus-Tilia stands, on soil, 03.09.2019, LE 321794.

Clitocybe candicans (Pers.) P. Kumm. Loknyanskiy district, stow Osinovik, core zone, $57.09917^{\circ} \mathrm{N}, 30.57722^{\circ}$ E, old-growth Populus tremula forest, on litter, 13.09.2019, LE 321797; stow Slepetnoe, core zone, $57.08389^{\circ} \mathrm{N}$, $30.50528^{\circ} \mathrm{E}$, Alnus glutinosa forest, on litter, 03.09.2019, LE 321796.

Clitocybe inornata (Sowerby) Gillet Loknyanskiy district, stow Osinovik, core zone, $57.09861^{\circ} \mathrm{N}, 30.57611^{\circ} \mathrm{E}$, coniferous forest with Quercus robur in undergrowth, on litter, 13.09.2019, LE 321798.

Clitocybe phyllophila (Pers.) P. Kumm. Loknyanskiy district, trail «Put' mokhovikov», buffer zone, $57.07194^{\circ} \mathrm{N}, 30.60639^{\circ} \mathrm{E}$, Alnus glutinosa forest, on litter, 11.09.2019, LE 321799.

Coprinopsis stercorea (Fr.) Redhead, Vilgalys \& Moncalvo - Loknyanskiy district, stow Dubovets, core zone, $57.08278^{\circ} \mathrm{N}$, $30.64778^{\circ}$ E, coniferous forest with Populus tremula and Corylus avellana, on elk faeces, 09.09.2019, LE 321800.

Cortinarius acutus (Pers.) Fr. - Loknyanskiy district, stow Slepetnoe, core zone, $57.08389^{\circ} \mathrm{N}$, $30.50528^{\circ} \mathrm{E}$, Alnus glutinosa forest, on soil, 03.09.2019, LE 330201.

Cortinarius alnetorum (Velen.) M.M. Moser - Loknyanskiy district, stow Slepetnoe, core zone, $57.08389^{\circ} \mathrm{N}, 30.50528^{\circ} \mathrm{E}$, Alnus glutinosa forest, on soil, 03.09.2019, LE 330202.

Cortinarius argenteopileatus Nezdojm. Loknyanskiy district, stow Slepetnoe, core zone, $57.08361^{\circ} \mathrm{N}, 30.50611^{\circ}$ E, Quercus-Tilia stands, on soil, 03.09.2019, LE 330203.

Cortinarius evernius (Fr.) Fr. - Bezhanitskiy district, trail «Plavnitskoe boloto», buffer zone, 
$57.10194^{\circ} \mathrm{N}, 30.38972^{\circ} \mathrm{E}$, coniferous forest with Populus tremula, on soil, 06.09.2019, LE 330204.

Cortinarius fervidus P.D. Orton - Loknyanskiy district, stow Slepetnoe, core zone, $57.08389^{\circ} \mathrm{N}$, $30.50556^{\circ}$ E, coniferous forest with Populus tremula and Betula sp., in undergrowth - Tilia cordata, Sorbus aucuparia, Quercus robur, on soil, 03.09.2019, LE 330205.

Cortinarius flexipes (Pers.) Fr. - Loknyanskiy district, stow Slepetnoe, core zone, $57.08333^{\circ} \mathrm{N}$, $30.50472^{\circ}$ E, on the border of Sphagnum bog and mixed forest (Populus tremula, Picea abies), on soil, 03.09.2019, LE 330206.

Cortinarius glaucopus (Schaeff.) Gray Loknyanskiy district, stow Slepetnoe, core zone, $57.08389^{\circ} \mathrm{N}, 30.50556^{\circ} \mathrm{E}$, coniferous forest with Populus tremula and Betula sp., in undergrowth Tilia cordata, Sorbus aucuparia, Quercus robur, on soil, 03.09.2019, LE 330207.

Cortinarius lucorum (Fr.) Berger - Loknyanskiy district, stow Osinovik, core zone, $57.09944^{\circ} \mathrm{N}$, $30.57889^{\circ} \mathrm{E}$, Populus tremula forest with Corylus avellana, on soil, 13.09.2019, LE 330208.

Cortinarius paragaudis Fr. - Loknyanskiy district, stow Maloe Loshye, core zone, $57.09722^{\circ} \mathrm{N}$, $30.53056^{\circ}$ E, coniferous forest with Populus tremula and Betula sp., with Tilia cordata, Sorbus aucuparia, Quercus robur in undergrowth, on soil, 02.09.2019, LE 330209.

Cortinarius porphyropus (Alb. \& Schwein.) Fr. - Bezhanitskiy district, trail «Plavnitskoe boloto», buffer zone, $57.09889^{\circ} \mathrm{N}, 30.36944^{\circ} \mathrm{E}$, Populus tremula forest, on soil, 06.09.2019, LE 330210.

Cortinarius talus Fr. - Loknyanskiy district, stow Slepetnoe, core zone, $57.08333^{\circ} \mathrm{N}, 30.50611^{\circ} \mathrm{E}$, Tilia cordata forest, on soil, 03.09.2019, LE 330212; $57.08389^{\circ} \mathrm{N}, 30.50556^{\circ} \mathrm{E}$, coniferous forest with Populus tremula and Betula sp., with Tilia cordata, Sorbus aucuparia, Quercus robur in undergrowth, on soil, 03.09.2019, LE 330211.

Cortinarius torvus (Fr.) Fr. - Loknyanskiy district, stow Osinovik, core zone, 57.09944 $\mathrm{N}$, $30.57889^{\circ}$ E, old-growth Populus tremula forest with Corylus avellana, on soil, 13.09.2019, LE 330213.

Crepidotus applanatus (Pers.) P. Kumm. Loknyanskiy district, trail «Put' mokhovikov», buffer zone, $57.06876^{\circ} \mathrm{N}, 30.58568^{\circ} \mathrm{E}$, mixed forest, on rotten wood, 11.09.2019, LE 330214.

Crepidotus crocophyllus (Berk.) Sacc. Loknyanskiy district, stow Osinovik, core zone, $57.09861^{\circ} \mathrm{N}, 30.58111^{\circ} \mathrm{E}$, coniferous forest with Quercus robur in undergrowth, on trunk of Populus tremula, 13.09.2019, LE 330215.
Deconica phyllogena (Sacc.) Noordel. Loknyanskiy district, stow Dubovets, core zone, $57.07944^{\circ} \mathrm{N}, 30.67000^{\circ} \mathrm{E}$, secondary BetulaPopulus forest, on litter, 09.09.2019, LE 330216.

Entoloma dysthales (Peck) Sacc. - Loknyanskiy district, trail «Put' mokhovikov», buffer zone, $57.06666^{\circ} \mathrm{N}, 30.60454^{\circ} \mathrm{E}$, Populus tremula forest, on moss-covered hardwood trunk, 11.09.2019, LE 330217.

Entoloma rhodocylix (Lasch) M.M. Moser Loknyanskiy district, stow Osinovik, core zone, $57.09917^{\circ} \mathrm{N}, 30.57722^{\circ}$ E, old-growth Populus tremula forest, on moss-covered hardwood trunk, 13.09.2019, LE 330219; $57.09944^{\circ} \mathrm{N}$, $30.57889^{\circ}$ E, Populus tremula forest with Corylus avellana, on moss-covered hardwood trunk, 13.09.2019, LE 330218.

Entoloma sericellum (Fr.) P. Kumm. Loknyanskiy district, stow Sapozhok, core zone, $57.08250^{\circ} \mathrm{N}, 30.65278^{\circ} \mathrm{E}$, coniferous forest, on soil, 09.09.2019, LE 330220.

! Galerina caulocystidiata Arnolds. - Loknyanskiy district, stow Dubovets, core zone, $57.07944^{\circ} \mathrm{N}$, $30.67000^{\circ} \mathrm{E}$, secondary Betula-Populus forest, in Sphagnum, 09.09.2019, LE 330221.

The specimen is represented by three basidiomata. Pileus is $3-10 \mathrm{~mm}$ in diameter, conical becoming campanulate with a somewhat wavy margin, strongly hygrophanous: pale beige-orange in dry weather, fawn to lightbrown when wet, translucently striate. Stipe is $35-50 \times 1.5-2 \mathrm{~mm}$, cylindrical, almost concolorous with pileus, entirely pubescent. Lamellae are ventricose, light fawn, adnate to broadly adnate, rather distant. Basidiospores are 10.5$11.5 \times 6.3-7.0 \mu \mathrm{m}$, broadly amygdaliform, somewhat papillate, yellowish-brown in $\mathrm{KOH}$, rugulose (Fig. 4a). Basidia are 15-18 × 6-8 $\mu \mathrm{m}, 2$-spored, narrowly clavate (Fig. 4b). Cheilocystidia are abundant, forming a sterile edge, $36-45 \times 3-5 \times 9-15 \mu \mathrm{m}$, lageniform, with a widened base (Fig. 4c). Pleurocystidia are absent. Pileipellis is a cutis. Caulocystidia are numerous, 75-95 × 7-10 × 20-26 $\mu \mathrm{m}$, lageniform, slightly but distinctly capitate, with widened base (Fig. 4d). Clamps are abundant.

* Galerina hybrida Kühner - Bezhanitskiy district, trail «Plavnitskoe boloto», core zone, $57.10482^{\circ} \mathrm{N}, 30.38016^{\circ} \mathrm{E}$, Sphagnum bog, in Sphagnum, 06.09.2019, LE 330223; Loknyanskiy district, stow Dubovets, core zone, $57.08081^{\circ} \mathrm{N}$, $30.66209^{\circ}$ E, Sphagnum bog, in Sphagnum, 09.09.2019, LE 330222. 


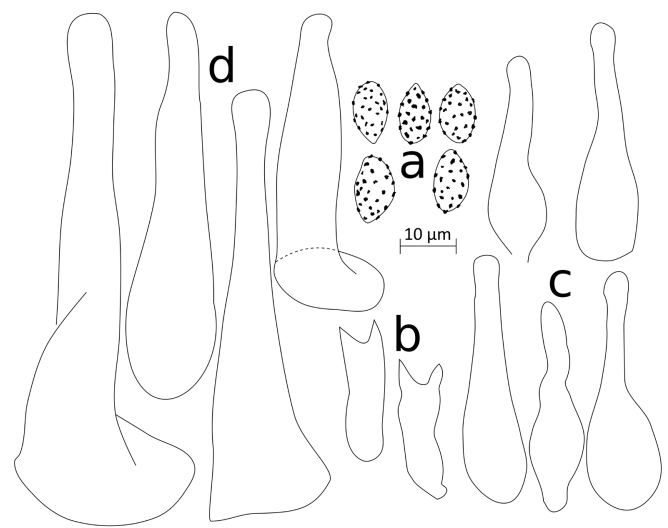

Fig. 4. Microscopic characteristics of Galerina caulocystidiata LE 330221; a - basidiospores, b - basidia, c - cheilocystidia, d - caulocystidia.

Galerina sphagnicola (G.F. Atk.) A.H. Sm. \& Singer - Loknyanskiy district, trail «Put' mokhovikov», core zone, $57.06722^{\circ} \mathrm{N}$, $30.58694^{\circ}$ E, Sphagnum bog, in Sphagnum, 11.09.2019, LE 330224.

Gamundia striatula (Kühner) Raithelh.-Loknyanskiy district, stow Osinovik, core zone, $57.09917^{\circ} \mathrm{N}$, $30.57722^{\circ}$ E, old-growth Populus tremula forest, on rotten wood, 13.09.2019, LE 330225.

* Gymnopus erythropus (Pers.) Antonín, Halling \& Noordel. - Loknyanskiy district, stow Slepetnoe, core zone, $57.08361^{\circ} \mathrm{N}$, $30.50611^{\circ} \mathrm{E}$, Quercus-Tilia stands, on litter, 03.09.2019, LE 330226.

Gymnopus terginus (Fr.) Antonín \& Noordel. - Loknyanskiy district, stow Slepetnoe, core zone, $57.08389^{\circ} \mathrm{N}, 30.50528^{\circ} \mathrm{E}$, Alnus glutinosa forest, on litter, 03.09.2019, LE 330227.

Helicogloea compressa (Ellis \& Everh.) V. Malysheva \& K. Põldmaa - Bezhanitskiy district, trail «Plavnitskoe boloto», buffer zone, $57.09889^{\circ} \mathrm{N}$, $30.36944^{\circ}$ E, Populus tremula forest, on rotten deciduous wood, 06.09.2019, LE 330228.

Hemistropharia albocrenulata (Peck) Jacobsson \& E. Larss. - Loknyanskiy district, stow Slepetnoe, core zone, $57.08389^{\circ} \mathrm{N}, 30.50556^{\circ} \mathrm{E}$, coniferous forest with Populus tremula and Betula sp., with Tilia cordata, Sorbus aucuparia, Quercus robur in undergrowth, at the base of old Populus tremula, 03.09.2019, LE 330229.

Hydropus marginellus (Pers.) Singer Loknyanskiy district, stow Osinovik, core zone, $57.09861^{\circ} \mathrm{N}, 30.58056^{\circ}$ E, Populus tremula forest with Picea abies and Quercus robur in undergrowth, on trunk of Populus tremula, 13.09.2019, LE 330232; trail «Put' mokhovikov», buffer zone, $57.07194^{\circ} \mathrm{N}$, $30.60639^{\circ}$ E, Betula-Populus forest, on trunk of Populus tremula, 11.09.2019, LE 330230; trail «Put' mokhovikov», buffer zone, $57.07278^{\circ} \mathrm{N}$, $30.59917^{\circ} \mathrm{E}$, Betula-Populus forest, on trunk of Populus tremula, 11.09.2019, LE 330231.

* Lacrymaria glareosa (J. Favre) Watling Loknyanskiy district, trail «Put' mokhovikov», buffer zone, $57.06611^{\circ} \mathrm{N}, 30.60806^{\circ} \mathrm{E}$, dirt roadside, on litter, 11.09.2019, LE 330233.

Lactarius aquizonatus Kytöv. - Bezhanitskiy district, trail «Plavnitskoe boloto», core zone, $57.10167^{\circ} \mathrm{N}, 30.39167^{\circ} \mathrm{E}$, on the border of Sphagnum bog and mixed forest (Populus tremula, Picea abies), on soil, 06.09.2019, LE 330234.

Lactarius glyciosmus (Fr.) Fr. - Loknyanskiy district, trail «Put' mokhovikov», core zone, $57.06876^{\circ} \mathrm{N}, 30.58568^{\circ} \mathrm{E}$, secondary BetulaPopulus forest, on soil, 11.09.2019, LE 330235.

Lactarius hysginus (Fr.) Fr. - Loknyanskiy district, stow Dubovets, core zone, $57.07806^{\circ} \mathrm{N}$, $30.66972^{\circ} \mathrm{E}$, coniferous forest, on soil, 09.09.2019, LE 330236.

Lactarius spinosulus Quél. \& Le Bret. - Bezhanitskiy district, trail «Plavnitskoe boloto», buffer zone, $57.09748^{\circ} \mathrm{N}, 30.37416^{\circ} \mathrm{E}$, secondary BetulaPopulus forest, on soil, 06.09.2019, LE 330237.

Lactarius tabidus Fr. - Loknyanskiy district, stow Dubovets, core zone, $57.07806^{\circ} \mathrm{N}$, $30.66972^{\circ} \mathrm{E}$, coniferous forest, on soil, 09.09.2019, LE 330238; stow Osinovik, core zone, $57.09944^{\circ} \mathrm{N}, 30.57889^{\circ}$ E, Populus tremula forest with Corylus avellana, on soil, 13.09.2019, LE 330239.

Lactarius vietus (Fr.) Fr. - Loknyanskiy district, trail «Put' mokhovikov», buffer zone, $57.06583^{\circ} \mathrm{N}, 30.59361^{\circ} \mathrm{E}$, on the border of Sphagnum bog and mixed forest (Populus tremula, Picea abies), on soil, 11.09.2019, LE 330241 ; stow Slepetnoe, core zone, $57.08333^{\circ} \mathrm{N}$, $30.50472^{\circ} \mathrm{E}$, Alnus glutinosa forest, on soil, 03.09.2019, LE 330240.

* Lepiota boudieri Bres. - Loknyanskiy district, trail «Put' mokhovikov», buffer zone, $57.10417^{\circ} \mathrm{N}, 30.37083^{\circ} \mathrm{E}$, secondary BetulaPopulus forest, on litter, 11.09.2019, LE 330242.

Lyophyllum boudieri Kühner \& Romagn. Loknyanskiy district, stow Dubovets, core zone, $57.07806^{\circ} \mathrm{N}, 30.66972^{\circ} \mathrm{E}$, coniferous forest, on litter, 09.09.2019, LE 330243.

Lyophyllum rancidum (Fr.) Singer - Loknyanskiy district, trail «Put' mokhovikov», buffer zone, $57.07110^{\circ} \mathrm{N}, 30.59450^{\circ} \mathrm{E}$, secondary BetulaPopulus forest, on litter, 11.09.2019, LE 330244. 
Lyophyllum tylicolor (Fr.) M. Lange \& Sivertsen - Loknyanskiy district, stow Osinovik, core zone, $57.09861^{\circ} \mathrm{N}, 30.57611^{\circ} \mathrm{E}$, coniferous forest with Quercus robur in undergrowth, on litter, 13.09.2019, LE 330245.

Mycena flavoalba (Fr.) Quél. - Bezhanitskiy district, trail «Plavnitskoe boloto», buffer zone, $57.09833^{\circ} \mathrm{N}, 30.37194^{\circ} \mathrm{E}$, Populus tremula forest, on litter, 06.09.2019, LE 330246; Loknyanskiy district, stow Dubovets, core zone, $57.08278^{\circ} \mathrm{N}$, $30.64778^{\circ}$ E, Populus tremula forest with Corylus avellana, on litter, 09.09.2019, LE 330247.

Mycenella lasiosperma (Bres.) Locq. Loknyanskiy district, stow Dubovets, core zone, $57.07944^{\circ} \mathrm{N}, 30.67000^{\circ} \mathrm{E}$, secondary BetulaPopulus forest, on trunk of Populus tremula, 09.09.2019, LE 330248.

Panaeolus alcis M.M. Moser - Loknyanskiy district, stow Sapozhok, core zone, $57.07750^{\circ} \mathrm{N}$, $30.66972^{\circ} \mathrm{E}$, coniferous forest with Corylus avellana, on elk dung, 09.09.2019, LE 330249.

Phaeoclavulina flaccida (Fr.) Giachini-Loknyanskiy district, stow Sapozhok, core zone, $57.08278^{\circ} \mathrm{N}$, $30.64778^{\circ}$ E, Populus tremula forest with Corylus avellana, on soil, 09.09.2019, LE 330250.

Phaeogalera stagnina (Fr.) Pegler \& T.W.K. Young - Loknyanskiy district, stow Dubovets, core zone, $57.08081^{\circ}$ N, $30.66209^{\circ}$ E, Sphagnum bog, in Sphagnum, 09.09.2019, LE 330251.

Pholiota astragalina (Fr.) Singer - Loknyanskiy district, trail «Put' mokhovikov», buffer zone, $57.07110^{\circ} \mathrm{N}, 30.59450^{\circ} \mathrm{E}$, coniferous forest with Populus tremula, on rotten wood, 11.09.2019, LE 330252.

Pholiota conissans (Fr.) Kuyper \& Tjall.Beuk. - Loknyanskiy district, trail «Put' mokhovikov», buffer zone, $57.06583^{\circ} \mathrm{N}, 30.59972^{\circ} \mathrm{E}$, secondary Betula-Populus forest, on rotten wood, 11.09.2019, LE 330253.

Pluteus hispidulus (Fr.) Gillet - Loknyanskiy district, trail «Put' mokhovikov», core zone, $57.06583^{\circ} \mathrm{N}, 30.59361^{\circ} \mathrm{E}$, on the border of Sphagnum bog and mixed forest (Populus tremula, Picea abies), on trunk of Populus tremula, 11.09.2019, LE 330254.

Pluteus podospileus Sacc. \& Cub. Loknyanskiy district, stow Dubovets, core zone, $57.07944^{\circ} \mathrm{N}, 30.67000^{\circ} \mathrm{E}$, secondary BetulaPopulus forest, on rotten wood, 09.09.2019, LE 330255; trail «Put' mokhovikov», buffer zone, $57.07194^{\circ} \mathrm{N}, 30.60639^{\circ} \mathrm{E}$, Alnus glutinosa forest, on rotten wood, 11.09.2019, LE 330256.

Pluteus semibulbosus (Lasch) Quél. Loknyanskiy district, stow Dubovets, core zone, $57.07944^{\circ} \mathrm{N}, 30.67000^{\circ} \mathrm{E}$, secondary Betula-Populus forest, on trunk of Populus tremula, 09.09.2019, LE 330257.

* Pluteus velutinus C.K. Pradeep, Justo \& K.B. Vrinda - Loknyanskiy district, trail «Put' mokhovikov», buffer zone, $57.06556^{\circ} \mathrm{N}$, $30.60694^{\circ}$ E, Populus tremula forest, on rotten wood, 11.09.2019, LE 330258.

Psathyrella piluliformis (Bull.) P.D. Orton Loknyanskiy district, stow Sapozhok, core zone, $57.08278^{\circ} \mathrm{N}, 30.64778^{\circ} \mathrm{E}$, Populus tremula forest with Corylus avellana, on rotten wood, 09.09.2019, LE 330259.

! Pseudobaeospora celluloderma Bas - Bezhanitskiy district, trail «Plavnitskoe boloto», buffer zone, $57.10389^{\circ} \mathrm{N}, 30.36944^{\circ} \mathrm{E}$, secondary meadow, on herbal remnants, 06.09.2019, LE 330260.

The specimen is represented by two basidiomata. Pileus is $3-5 \mathrm{~mm}$ in diameter, almost flat, somewhat lilaceous; stipe 10-25 $\times 0.5-1$ $\mathrm{mm}$, cylindrical, concolorous with cap, fibrillose. Lamellae are ventricose, concolorous with pileus, emarginate, sometimes with a small decurrent tooth, distant. Basidiospores are $3.8-4.2 \times 2.7-3.0 \mu \mathrm{m}$, very broadly ellipsoid, thin-walled, hyaline (in preparation made of lamellae), or thick-walled and slightly dextrinoid in preparations made of the stipe surface (Fig. 5a). Basidia are 16-25 × 4-5 $\mu \mathrm{m}, 4$-spored, narrowly clavate to almost cylindrical (Fig. 5b). Cheilocystidia and pleurocystidia are absent. Pileipellis is a hymeniderm with terminal cells 12.3-27.3 × 8.3-12.2 $\mu \mathrm{m}$, clavate to subglobose, sometimes pedunculate (Fig. 5d). Caulocystidia are $25-33 \times 5-8 \mu \mathrm{m}$, filiform, clavate to subclavate, sometimes swollen at the base (Fig. 5c).

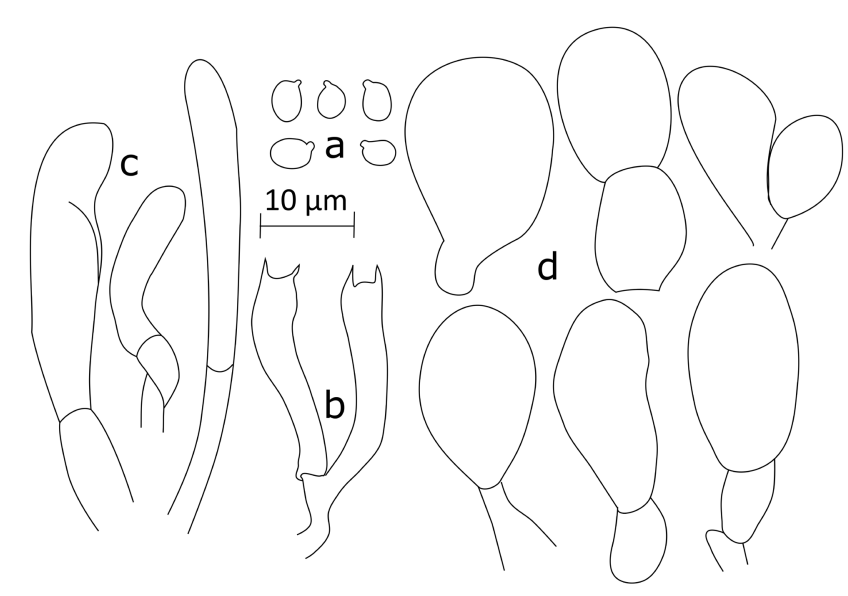

Fig. 5. Microscopic characteristics of Pseudobaeospora celluloderma LE 330260; a - basidiospores, b - basidia (only two sterigmata shown), $\mathrm{c}-$ caulocystidia, $\mathrm{d}$ - elements of pileipellis. 
Psilocybe turficola J. Favre - Loknyanskiy district, stow Maloe Loshye, core zone, $57.09722^{\circ} \mathrm{N}$, $30.53056^{\circ}$ E, coniferous forest with Populus tremula and Betula sp., with Tilia cordata, Sorbus aucuparia, Quercus robur in undergrowth, in Sphagnum, 02.09.2019, LE 330261.

* Rugosomyces obscurissimus (A. Pearson) Bon - Loknyanskiy district, stow Osinovik, core zone, $57.09861^{\circ} \mathrm{N}, 30.58056^{\circ} \mathrm{E}$, Populus tremula forest with Picea abies and Quercus robur in undergrowth, on soil, 13.09.2019, LE 330262.

Russula betularum Hora - Loknyanskiy district, stow Dubovets, core zone, $57.07806^{\circ} \mathrm{N}, 30.66972^{\circ} \mathrm{E}$, coniferous forest, on soil, 09.09.2019, LE 330263.

Russula gracillima Jul. Schäff. - Bezhanitskiy district, trail «Plavnitskoe boloto», buffer zone, $57.10194^{\circ} \mathrm{N}, 30.38972^{\circ} \mathrm{E}$, coniferous forest with Populus tremula, on soil, 06.09.2019, LE 330264.

Simocybe haustellaris (Fr.) Watling Loknyanskiy district, stow Dubovets, core zone, $57.07944^{\circ} \mathrm{N}, 30.67000^{\circ} \mathrm{E}$, Populus forest with Betula sp., on rotten wood, 09.09.2019, LE 330266; stow Osinovik, core zone, $57.09861^{\circ} \mathrm{N}$, $30.58056^{\circ}$ E, Populus forest with Picea abies and Quercus robur in undergrowth, on rotten wood, 13.09.2019, LE 330265.

Stropharia alcis Kytöv. - Loknyanskiy district, stow Dubovets, core zone, $57.08278^{\circ} \mathrm{N}$, $30.64778^{\circ}$ E, Populus tremula forest with Corylus avellana, on elk dung, 09.09.2019, LE 330268; trail «Put' mokhovikov», core zone, $57.06583^{\circ} \mathrm{N}$, $30.59361^{\circ} \mathrm{E}$, on the border of Sphagnum bog and mixed forest (Populus tremula, Picea abies), on elk dung, 11.09.2019, LE 330269; stow Slepetnoe, core zone, $57.08389^{\circ} \mathrm{N}, 30.50528^{\circ} \mathrm{E}$, Alnus glutinosa forest, on elk faeces, 03.09.2019, LE 330267.

Tomentella lapida (Pers.) Stalpers - Loknyanskiy district, stow Osinovik, core zone, $57.09861^{\circ} \mathrm{N}$, $30.57611^{\circ} \mathrm{E}$, coniferous forest with Quercus robur in undergrowth, on rotten deciduous wood, 13.09.2019, LE 330270.

Tricholoma columbetta (Fr.) P. Kumm. Bezhanitskiy district, trail «Plavnitskoe boloto», buffer zone, $57.10389^{\circ} \mathrm{N}, 30.36944^{\circ} \mathrm{E}$, secondary meadow, on soil, 06.09.2019, LE 330271.

Tricholoma frondosae Kalamees \& Shchukin - Loknyanskiy district, stow Slepetnoe, core zone, $57.08361^{\circ} \mathrm{N}, 30.50611^{\circ}$ E, Quercus-Tilia stands, on soil, 03.09.2019, LE 330272.

Tricholoma saponaceum (Fr.) P. Kumm. Bezhanitskiy district, trail «Plavnitskoe boloto», core zone, $57.10167^{\circ} \mathrm{N}, 30.39167^{\circ} \mathrm{E}$, on the border of Sphagnum bog and mixed forest (Populus tremula, Picea abies), on soil, 06.09.2019, LE 330273; Loknyanskiy district, stow Sapozhok, core zone, $57.08278^{\circ} \mathrm{N}, 30.64778^{\circ} \mathrm{E}$, coniferous forest with Populus tremula and Corylus avellana, on soil, 09.09.2019, LE 330274.

Xenasma pruinosum (Pat.) Donk - Bezhanitskiy district, trail «Plavnitskoe boloto», core zone, $57.09889^{\circ} \mathrm{N}, 30.36944^{\circ} \mathrm{E}$, Populus forest, on rotten deciduous wood, 06.09.2019, LE 330275.

\section{Discussion}

Any reasonable analysis of a community structure is impossible without previous inventory studies and the fullest possible revealing of a species list. Nowadays, in many relatively sufficient studied PAs in Russia, the number of known basidiomycete species is more than 200 . Our study, comprising 74 species, is obviously insufficient for any community analysis or revealing the peculiarities of the PSNR fungi. Nevertheless, even the incomplete existing check-list has resulted in new fungi for the whole country and other noteworthy species.

Basidiomycetes new to Russia

Of the 74 basidiomycetes presented in the paper, four species were recorded for the first time in Russia. Below, we discuss their history, distribution, habitats, similar or closely related species and current state of knowledge.

Achroomyces effusus was described from Poland. It is currently known from several European countries (Wojewoda, 1977; Jülich, 1984; Tejklová \& Zíbarová, 2018), being likely overlooked due to inconspicuous basidiomata. Wojewoda (1977) mentioned that there may be two species under this name, as there are conflicting reports on the presence or absence of clamps on hyphae. In our specimen, clamps are present. In addition, this species was synonymised with Colacogloea peniophorae (Bourdot \& Galzin) Oberw., R. Bauer \& Bandoni (Krieglsteiner, 2000). The latter parasitises on corticiod fungi (Oberwinkler et al., 1990), and belongs to the Microbotryomycetes (Aime et al., 2014), whereas A. effusus is considered to be in the Pucciniomycetes. As there have not been any recent taxonomic studies of the Platygloeaceae, we take treat species according to the available taxonomic work based on morphological features only.

This species is associated with dead trunks and branches of deciduous trees, less often conifers. Thus, the most common species is reported from wood with Alnus incana (Bourdot \& Galzin, 1928; Wojewoda, 1977; Jülich, 1984; Tejklová \& Zíbarová, 2018). There are records on Fagus sylvatica L. (Christiansen, 1959; 
Ingold, 1988), Sambucus sp. (Altermatt \& Mornand, 1991), Abies alba Mill. (Christiansen, 1959). Our record was made on an unidentified deciduous wood, most probably Populus tremula, which is a new, not previously noted, substrate for this species. There is almost no information on vegetation conditions, usually general mentioning like deciduous and coniferous forests. In Slovakia, A. effusus is known in swamp-fen alder carr (Tejklová \& Zíbarová, 2018). Our record was made at the border of a Populus tremula - Picea abies forest with a bog, but relatively nearby were also fens with Alnus glutinosa forest.

Botryobasidium stigmatisporum was described from Réunion in the Indian Ocean (east of Madagascar) (Boidin \& Gilles, 1988). Besides the type locality, in the Southern Hemisphere, the species is known from Argentina (Greslebin \& Rajchenberg, 2003). In Europe, the species has been recorded in France and Slovakia (Hagara, 2001; Bernicchia \& Gorjón, 2010). Our record, about $1300 \mathrm{~km}$ from the nearest location, in Slovakia, considerably extends the known range of the species in Europe eastwards and northwards.

How to separate $B$. stigmatisporum from similar species is unclear. Another European species, $B$. asperulum (D.P. Rogers) Boidin, has finely ornamented ellipsoid to subglobose spores, measuring 4.5-5.5 × 3.5-4.5 $\mu \mathrm{m}$. Botryobasidium stigmatisporum spores are ellipsoid to ovoid, with very fine ornamentation and measure 5.2-6.7(7) $\times 3.2-4.3 \mu \mathrm{m}$ (Langer, 1994; Bernicchia \& Gorjón, 2010). Thus, these two species differ in spore shape and size. On the basis of the shape and length of the spores, we identified our specimen as B. stigmatisporum.

According to Hjortstam (1983), B. asperulum is very close to Botryobasidium pruinatum (Bres.) J. Erikss. and Botryobasidium laeve (J. Erikss.) Parmasto. The verruculose spores form an only difference. According to Maekawa (1990), the holotypes of $B$. asperulum, B. laeve and B. pruinatum all have ornamented spores in scanning electron microscopy (SEM) and are indistinguishable microscopically. Thus, they should be synonyms with the priority of $B$. pruinatum. A SEM study revealed that the spores of Botryobasidium medium J. Erikss.'s holotype are also ornamented (Maekawa, 1991).

There is no mention of any molecular studies of this group of Botryobasidium species in the available literature. A large-scale molecular study of this group is necessary to identify taxonomically important morphological features of individual species in this genus. Here, we adopt the concept of this group proposed by Langer (1994).
Botryobasidium stigmatisporum is reported to be an indiscriminate species that develops on numerous woody substrates. Due to the considerable geographical distribution of the known locations, the range of substrates is very wide, including both deciduous and coniferous species. In Réunion, the species is recorded on Philippia sp. (Ericaceae), in Argentina on Austrocedrus chilensis (D.Don) Pic. Serm. \& Bizzarri (Cupressaceae) (Boidin \& Gilles, 1988; Greslebin \& Rajchenberg, 2003). A record in Slovakia has been discovered on burnt twigs of Quercus sp. (Hagara, 2001). The vegetation conditions, in which this species is observed, vary drastically, from tropical rainforests to temperate forests in the Andes Mountains and in Europe. Our record is very close to that in Slovakia. Unfortunately, it was not possible to identify the substrate accurately. Most likely it is Quercus robur.

Galerina caulocystidiata was described from the Netherlands (Arnolds, 1982). It is also known from Poland (Gierczyk et al., 2019), the Czech Republic (Tejklová, 2018), Belgium (Walleyn \& Vandeven, 2006), and Germany (Lüderitz et al., 2016). According to Arnolds (1982), typical features of the species are the absence of pleurocystidia and the presence of a well-developed veil. In our specimen, no veil or its remnants were observed. However, since the presence of the veil is probably an unreliable taxonomic character (Arnolds \& De Vries, 1998), we consider the studied specimen to be G. caulocystidiata due to the total absence of pleurocystidia.

There is no information on habitat of the species neither in the protologue (Arnolds, 1982) nor on the Belgian checklist (Walleyn \& Vandeven, 2006). A more or less detailed description of G. caulocystidiata's habitat is given for Poland, namely «near mouth of Beskidnik stream; spruce brushwood; mosses» (Gierczyk et al., 2019). For the Czech record, there is a description of the studied locality as «dry meadow». But no precise information on $G$. caulocystidiata's habitat can be found in Tejklová (2018). A similar situation with the German record, information about which is present in results of mycological workshops conducted near the town of Leck, Schleswig-Holstein. The studied areas represent «inland and coastal dunes as well as the expanding dunes of the Isle of Amrum and the Isle of Sylt» (Lüderitz et al., 2016). Detailed descriptions of habitats are given for several species, but not for G. caulocystidiada. Only a total list of macromycetes found in the area of Leckfeld-North in 1989-2015 includes G. caulocystidiat $a$ with no additional information except the note 
that the species is not indicated on the Red lists of Germany nor Schleswig-Holstein. We have found the specimen in Sphagnum in a secondary BetulaPopulus forest located at the edge of an inner mineral island. Our habitat is much more similar to the Polish location, but not exactly the same. The Czech habitat differs considerably. It allows us to assume that the species is not habitat-specific. However, there is another and more realistic possibility. The precise locality of the Czech record may be some place with mosses, not a dry meadow.

The species is very similar to the widely distributed and common Galerina vittiformis (Fr.) Singer, and differs from the latter only by the total absence of pleurocystidia. Thus, it is impossible to identify the species in the field, meaning G. caulocystidiata is likely a more widespread species, overlooked due to its striking similarity to $G$. vittiformis

Pseudobaeospora celluloderma is described from Great Britain (Bas, 2002). The species has been reported from Germany, Finland, Sweden (Bas, 2003), and Slovakia (Adamčík et al., 2007b). Pseudobaeospora celluloderma is the fourth species of the genus known in Russia (Singer, 1938; Vasilyeva, 1973; Morozova \& Popov, 2013). Due to the tiny size of basidiomata (pileus diameter is usually less than 5-6 mm), purple or lilac colour, distant lamellae $(\mathrm{L}=15-17)$ and hygrophanous, translucently striate pileus, the species can be easily identified in the field (Adamčík et al., 2007b). Conspicuous microscopical features are the absence of hymenial cystidia, pileipellis as irregular hymeniderm with very broadly clavate to subglobose terminal cells; the unique spores are hyaline and thin-walled in young specimens becoming slightly dextrinoid and thick-walled after discharge from the sterigmata.

Bas (2003) provided a quite wide diversity of habitats for $P$. celluloderma, ranging from woody debris in various types of forests and ruderal places to felted turf in moist meadows, with preference to calcareous and rich soils. Adamčík et al. (2007b) found the species mostly in various meadows, old pastures among different herbaceous plants. Also, they mentioned that the basidiomata were terrestrial, predominantly on peaty soils. Our specimen was found on herbal remnants in a secondary meadow. On the basis of the current state of knowledge, the typical habitat of the species can be described as meadow on peaty soil.

\section{Noteworthy species}

In addition to the species discussed above, several more records are noteworthy. Below is a list of six species new to Northwestern European Russia, with brief comments.

Galerina hybrida is closely related to Galerina tibiicystis (G.F. Atk.) Kühner. It differs from the latter by narrower spores stretched out into the callus (Gulden, 2010). It is a sphagnicolous species, considered being common in raised bogs (Gulden, 2010; Vašutová et al., 2013).

Gymnopus erythropus is widespread in temperate regions of Europe. The species can be easily recognised by its smooth dark reddish-brown stipe (Antonín \& Noordeloos, 2010). It develops on humus in deciduous forests, also on fallen branches of hardwood trees.

Lepiota boudieri is very closely related to the more common L. castanea Quél. These two species are almost indistinguishable in the field. Fortunately, the clamped hyphae of the pileipellis make the species easily identifiable microscopically (Noordeloos et al., 2001). It is a saprotrophic species, preferring rich soils in various forest types.

Pluteus velutinus was described recently from India (Pradeep et al., 2012). A remarkable feature is the peculiar shape of pleurocystidia with apical digitate projections. It is a lignicolous species. But it was also reported growing on litter (Malysheva et al., 2016).

Rugosomyces obscurissimus is distinguished by its relatively dark, purplish brown, purplish black pileus and slightly paler fibrillose stipe. Key microscopical features include hymeniderm pileipellis made up of sphaeropedunculate elements and cylindrical to subconical hyaline spores. It is a saprobic species. It develops on litter in forests and on unfertilised pastures (Knudsen \& Vesterholt, 2012).

Simocybe haustellaris has tiny pruinose sporocarps (pileus is up to $10 \mathrm{~mm}$ ) with eccentric stipe. It is a saprobic species on deciduous wood, common and widespread in temperate regions. It is probably overlooked.

Hemistropharia albocrenulata, Helicogloea compressa, and Xenasma pruinosum are noteworthy as threatened or rarely registered in Russia. Hemistropharia albocrenulata usually develops at the bases of old-growth living Populus tremula, and it is considered as vulnerable and as a species under strict protection according to the Finnish nature conservation decree (Hyvärinen et al., 2019), and in Novgorod region and Leningrad region in Russia (Vetkin et al., 2015; Geltman, 2018). Helicogloea compressa is registered for the second time in Russia, with a first record in Saint Petersburg (Spirin et al., 2018). Probably the species is overlooked. Xenasma pruinosum is a corticioid species, wide- 
ly distributed around the world and known from Asia, Europe, Africa, North and South America (Oberwinkler, 1965; Domański, 1992; Dai, 2011). In Russia, it is reported from seven regions, including the most recent mention from Leningrad region (Kotkova, 2020). Most likely, surveys overlook the species due to its small size, pale grey to bluish-grey basidiomata. It is readily recognised by the minutely encrusted pleural basidia (observed in Cotton Blue), ellipsoid spores, and basally slightly thick-walled pseudocystidia with an amorphous apical globule (Oberwinkler, 1965; Hjortstam et al., 1988). It is a saprobic species developing on deciduous, rarely on coniferous wood.

\section{Conclusions}

Currently, 992 species of Agaricomycetes, including the 74 species presented in the paper, are known in the Pskov region. Six species (Galerina hybrida, Gymnopus erythropus, Lepiota boudieri, Pluteus velutinus, Rugosomyces obscurissimus, Simocybe haustellaris) are new to Northwestern European Russia, and four species (Achroomyces effusus, Botryobasidium stigmatisporum, Galerina caulocystidiata, Pseudobaeospora celluloder$m a$ ) were recorded for the first time in Russia. In many well-studied Protected Areas, the number of known basidiomycete species exceeds 200, meaning that the fungal diversity of the Polistovskiy State Nature Reserve needs further investigation. The authors plan to continue their studies in the near future.

\section{Acknowledgements}

The authors are very grateful to Vera F. Malysheva (Komarov Botanical Institute of RAS, Russia) for the identification of Achroomyces effusus. The first author also would like to thank Svetlana Yu. Igosheva (Senior Researcher of the Polistovskiy State Nature Reserve, Russia) for the opportunity to work in the Protected Area, inspectors of the PSNR as well as volunteers Ekaterina Knorring (Russia) and Alexandra Volkova (Russia) for their valuable help during field work. The study has been carried out within the framework of the institutional research project of the Komarov Botanical Institute (AAAA-A19-119020890079-6) and partly supported by the Russian Foundation for Basic Researches, project No. 20-0400349 using the equipment of the Core Facility Centre «Cell and Molecular Technologies in Plant Science» at the Komarov Botanical Institute, RAS (St. Petersburg, Russia).

\section{References}

Adamčík S., Christensen M., Heilmann-Clausen J., Walleyn R. 2007a. Fungal diversity in the Poloniny National Park with emphasis on indicator species of conservation value of beech forests in Europe. Czech Mycology 59(1): 67-81.
Adamčík S., Ripková S., Kučera V. 2007b. Re-evaluation of morphological variability of Pseudobaeospora group Celluloderma (Agaricales, Basidiomycota). Nova Hedwigia 85(3): 365-377. DOI: 10.1127/00295035/2007/0085-0365

Aime M.C., Toome M., McLaughlin D.J. 2014. Pucciniomycotina. In: D.J. McLaughlin, J.W. Spatafora (Eds.): Systematics and Evolution: Part A. The Mycota. Vol. 7. Berlin, Heidelberg: Springer. P. 271-294. DOI: 10.1007/978-3-642-55318-9_10

Altermatt C., Mornand J. 1991. Contribution à la connaissance des champignons de Maine-et-Loire. 1. Aphyllophoromycetidae (Rea) Bon p.p. Auriculariomycetidae Locq. p.p. Bulletin de la Société Mycologique de France 107(2): 53-84.

Antonín V., Noordeloos M.E. 2010. A monograph of marasmioid and collybioid fungi in Europe. Eching: IHWVerlag. 478 p.

Arnolds E. 1982. Ecology and coenology of macrofungi in grasslands and moist heathlands in Drenthe, the Netherlands. Part 2. Autecology. Part 3. Taxonomy. Bibliotheca Mycologica. Vol. 90. Vaduz: J. Cramer. 501 p.

Arnolds E., De Vries B. 1998. On the identity of the new taxa of Galerina (Agaricales) provisionally described by J.J. Barkman. Persoonia 17(1): 1-28.

Aučina A., Rudawska M., Wilgan R., Janowski D., Skridaila A., Dapkūnienė S., Leski T. 2019. Functional diversity of ectomycorrhizal fungal communities along a peatland-forest gradient. Pedobiologia 74: 15-23. DOI: 10.1016/j.pedobi.2019.03.001

Baird R., Stokes C.E., Wood-Jones A., Alexander M., Watson C., Taylor G., Johnson K., Remaley T., Diehl S. 2014. Fleshy Saprobic and Ectomycorrhizal Fungal Communities Associated with Healthy and Declining Eastern Hemlock Stands in Great Smoky Mountains National Park. Southeastern Naturalist 13(6): 192-218. DOI: 10.1656/058.013.s613

Bas C. 2002. A reconnaissance of the genus Pseudobaeospora in Europe I. Persoonia 18(1): 115-122.

Bas C. 2003. A reconnaissance of the genus Pseudobaeospora in Europe II. Persoonia 18(2): 163-199.

Bernicchia A., Gorjón S.P. 2010. Corticiaceae s.l. Fungi Europaei. Vol. 12. Alassio: Edizioni Candusso. 1008 p.

Bogdanovskaya-Guiheneuf I.D. 1969. Patterns of Sphagnum bogs formation on the example of the PolistovoLovatsky massif. Leningrad: Nauka. 186 p. [In Russian]

Boidin J., Gilles G. 1988. Basidiomycètes Aphyllophorales de l'île de la Réunion: X. Compléments aux genres traités antérieurement (1re partie). Bulletin de La Société Mycologique de France 104(2): 59-71.

Bolshakov S.Yu., Volobuev S.V. 2016. New data on aphyllophoroid fungi of the Yamskaya Steppe (Belogorye Nature Reserve, Belgorod region). Bulletin of Bryansk Department of Russian Botanical Society 2(8): 18-25. [In Russian]

Bolshakov S.Yu., Volobuev S.V., Voronina E.Yu., Ezhov O.N., Kalinina L.B., Palamarchuk M.A., Palomozhnykh E.A., Potapov K.O., Shiryaeva O.S. 2019. Biodiversity of Agaricomycetes of European Russia: results 
and prospects of a data compilation project. In: Innovations and Traditions in Modern Botany (St. Petersburg, 21-25 October 2019). St. Petersburg: Komarov Botanical Institute. P. 13. [In Russian]

Bourdot H., Galzin A. 1928. Contribution a la flore mycologique de la France. I. Hymenomycètes de France. Hétérobasidiés - Homobasidiés gymnocarpes. Sceaux: Marcel Bry, Dessinateur Imprimeur. 761 p.

Brandrud T.E., Gorbunova I.A., Ageev D.V., Dahlberg A., Dima B., Morozova O.V., Svetasheva T.Yu. 2019. New data on Cortinarius funga (Agaricales, Basidiomycota) from Altaiskiy Nature Reserve and Gorno-Altaysk area (SW Siberia, Russia). Mikologiya i Fitopatologiya 53(6): 325-341. DOI: 10.1134/S0026364819060035

Christiansen M.P. 1959. Danish resupinate fungi. Part 1. Ascomycetes and Heterobasidiomycetes. Dansk Botanisk Arkiv 19(1): 5-55.

Dai Y.C. 2011. A revised checklist of corticioid and hydnoid fungi in China for 2010. Mycoscience 52(1): 69-79. DOI: 10.1007/S10267-010-0068-1

Domański S. 1992. Mała flora grzybów. Tom I. Basidiomycetes (Podstawczaki). Aphyllophorales (Bezblaszkowce). Czesść 7. Corticiaceae. Sarcodontia - Ypsilonidium, Christiansenia \& Syzygospora. Kraków: Polska Akademia Nauk, Instytut Botaniki im. W. Szafera. 258 p.

Erofeeva E.A., Bukharova N.V., Bulakh E.M. 2019. First data on basidial macromycetes at the cluster Zabelovsky of the Bastak Nature Reserve (Jewish Autonomous Region). Turczaninowia 22(1): 122-131. DOI: 10.14258/ turczaninowia.22.1.11 [In Russian]

Friedrich S. 2002. Selected Ascomycota and Basidiomycota from Cedynia Landscape Park (NW Poland). Polish Botanical Journal 47(2): 125-138.

Galanina O. 2005. The Polisto-Lovat' bog system. Stapfia 85: 247-254.

Geltman D.V. (Ed.). 2018. Red Data Book of the Leningrad region. Objects of plant world. St. Petersburg: Marafon. 840 p. [In Russian]

Gierczyk B., Kujawa A., Szczepkowski A., Ślusarczyk T., Pachlewski T., Chachuła P., Domian G. 2019. Macrofungi of the Bieszczady Mountains. Acta Mycologica 54(2): 1124. DOI: 10.5586/am.1124

Gogoi G., Parkash V. 2015. A checklist of gilled mushrooms (Basidiomycota: Agaricomycetes) with diversity analysis in Hollongapar Gibbon Wildlife Sanctuary, Assam, India. Journal of Threatened Taxa 7(15): 8272-8287. DOI: $10.11609 /$ jott.1770.7.15.8272-8287

Greslebin A.G., Rajchenberg M. 2003. Diversity of Corticiaceae sens. lat. in Patagonia, Southern Argentina. New Zealand Journal of Botany 41(3): 437-446. DOI: 10.1080/0028825X.2003.9512861

Gulden G. 2010. Galerinas in cold climates. North American Fungi 5(5): 127-157. DOI: 10.2509/naf2010.005.0058

Hagara L. 2001. Distribution of corticioid fungi in Slovakia: Botryobasidium and related genera. Catathelasma 1: 8-21.

Hansen L., Knudsen H. (Eds.). 1997. Nordic Macromycetes. Vol. 3. Heterobasidioid, aphyllophoroid and gastromycetoid basidiomycetes. Copenhagen: Nordsvamp. 444 p.
Hjortstam K. 1983. Studies in tropical Corticiaceae (Basidiomycetes) V. Specimens from East Africa collected by L. Ryvarden. Mycotaxon 17: 555-572.

Hjortstam K., Larsson K.-H., Ryvarden L. 1988. The Corticiaceae of North Europe. Vol. 8: Phlebiella; Thanatephorus - Ypsilonidium. Oslo: Fungiflora. P. 1450-1631.

Holec J., Kříž M., Pouzar Z., Šandová M. 2015. Boubínský prales virgin forest, a Central European refugium of boreal-montane and old-growth forest fungi. Czech Mycology 67(2): 157-226. DOI: 10.33585/cmy.67204

Hyvärinen E., Juslén A., Kemppainen E., Uddström A., Liukko U.-M. (Eds.). 2019. Suomen lajien uhanalaisuus - Punainen kirja 2019. The 2019 Red List of Finnish Species. Helsinki: Ministry of the Environment \& Finnish Environment Institute. 704 p.

Ingold C.T. 1988. Patterns of basidiospore germination in Platygloea effusa. Transactions of the British Mycological Society 91(1): 161-162. DOI: 10.1016/S00071536(88)80018-4

Iršènaitė R., Adamonytė G., Daniele I., Kasparavičius J., Kutorga E., Stončius D. 2013. Macromycetes and myxomycetes of Asveja Regional park (Lithuania). Botanica Lithuanica 19(1): 8-21. DOI: 10.2478/botlit-2013-0002

Ivoilov A.V., Bolshakov S.Yu., Silaeva T.B. 2017. Study of species diversity of macromycets. Saransk: Publisher of the Mordovia State University. 160 p. [In Russian]

Jülich W. 1984. Die Nichtblätterpilze, Gallertpilze und Bauchpilze. Aphyllophorales, Heterobasidiomycetes, Gastromycetes. Kleine Kryptogamenflora. Vol. 2b/1. Basidiomyceten. 1. Jena: G. Fischer. 626 p.

Karasiński D., Kujawa A., Piątek M., Ronikier A., Wołkowycki M. 2009. Contribution to biodiversity assessment of European primeval forests: new records of rare fungi in the Białowieża Forest. Polish Botanical Journal 54(1): 55-97.

Knudsen H., Vesterholt J. (Eds.). 2012. Funga Nordica. Agaricoid, boletoid, clavarioid, cyphelloid and gastroid genera. Copenhagen: Nordsvamp. 1083 p.

Kotkova V.M. 2014. Fungi of the Central-Forest State Nature Reserve (annotated list of species). Moscow. 94 p. [In Russian]

Kotkova V.M. 2020. New data on aphyllophoroid fungi (Basidiomycota) of the State Nature Reserve «Kurgalsky» (Leningrad Region). Novosti Sistematiki Nizshikh Rastenii 54(1): 78-86. [In Russian]

Kotkova V.M., Popov E.S. 2012. Aphyllophoroid fungi. Proceedings of the Sebezhsky National Park 2: 61-91. [In Russian]

Kotkova V.M., Popov E.S. 2013. Aphyllophoraceous fungi of Pskov Region. Novosti Sistematiki Nizshikh Rastenii 47: 87-121. DOI: 10.31111/nsnr/2013.47.87 [In Russian]

Kovalenko A.E., Kolmakov P.Yu., Morozova O.V., Popov E.S. 2003. Macromycetes of the Sebezhsky National Park. Mikologiya i Fitopatologiya 37(5): 37-48. [In Russian]

Krieglsteiner G.J. 2000. Die Großpilze Baden-Württembergs. Band 1: Allgemeiner Teil. Ständerpilze: Gallert-, Rinden-, Stachel- und Porenpilze. Stuttgart: E. Ulmer. 629 p.

Kunttu P., Kulju M., Kotiranta H. 2015. Checklist of aphyllophoroid fungi (Basidiomycota) of the Archipelago Sea National Park, Southwest Finland. Check List 11(2): 1587. DOI: 10.15560/11.2.1587 
Lacheva M., Radoukova T. 2014. Fungal diversity of Chivira Protected Area, Mt Sredna Gora, Bulgaria. International Journal of Biological Sciences 1(3): 1-17.

Langer E., Langer G., Striegel M., Riebesehl J., Ordynets A. 2014. Fungal diversity of the Kellerwald-Edersee National Park - indicator species of nature value and conservation. Nova Hedwigia 99(1-2): 129-144. DOI: 10.1127/0029-5035/2014/0201

Langer G. 1994. Die Gattung Botryobasidium Donk (Corticiaceae, Basidiomycetes). Bibliotheca Mycologica. Vol. 158. Berlin, Stuttgart: J. Cramer. 459 p.

Lisiewska M., Tortić M. 1990. Macrofungi in Forest Associations of the Plitvička Jezera National Park (Croatia, Yugoslavia). Acta Botanica Croatica 49: 81-91.

Lodge D.J., Ammirati J.F., O’Dell T.E., Mueller G.M., Huhndorf S.M., Wang C.-J., Stokland J.N., Schmit J.P., Ryvarden L., Leacock P.R., Mata M., Umaña L., Wu Q., Czederpiltz D.L. 2004. Terrestrial and lignicolous macrofungi. In: G.M. Mueller, G.F. Bills, M.S. Foster (Eds.): Biodiversity of Fungi. Inventory and Monitoring Methods. Burlington: Academic Press. P. 127-172. DOI: 10.1016/B978-012509551-8/50011-8

Lüderitz M., Kamke M., Specht P., Ludwig E., Lehmann H., Schubert H., Richter H., Richter U. 2016. Ergebnisse des 4. und 5. Dünenpilzworkshops. Zeitschrift für Mykologie 82(2): 355-448.

Maekawa N. 1990. Redifinition of Botryobasidium pruinatum (Corticiaceae, Aphyllophorales) and its relationship to B. asperulum and B. laeve. Transactions of the Mycological Society of Japan 31(4): 467-478.

Maekawa N. 1991. Seven species of the genus Botryobasidium (Corticiaceae, Aphyllophorales) previously unreported from Japan. Transactions of the Mycological Society of Japan 32(1): 125-133.

Malysheva E.F., Malysheva V.F., Justo A. 2016. Observations on Pluteus (Pluteaceae) diversity in South Siberia, Russia: morphological and molecular data. Mycological Progress 15(8): 861-882. DOI: $10.1007 / \mathrm{s} 11557-016-1215-7$

Morozova O.V., Popov E.S. 2013. New records of two species of the genus Pseudobaeospora (Basidiomycota, Agaricales) from Russia. Novosti Sistematiki Nizshikh Rastenii 47: 127-134. [In Russian]

Noordeloos M.E., Kuyper Th.W., Vellinga E.C. (Eds.). 2001. Flora Agaricina Neerlandica. Critical monographs on families of agarics and boleti occurring in the Netherlands. Vol. 5. Agaricaceae. Lisse / Abingdon / Exton / Tokyo: A. A. Balkema Publishers. 169 p.

Oberwinkler F. 1965. Primitive Basidiomyceten. Revision einiger Formenkreise von Basidienpilzen mit plastischer Basidie. Sydowia 19(1-3): 1-72.

Oberwinkler F., Bauer R., Bandoni R.J. 1990. Colacogloea: a new genus in the auricularioid Heterobasidiomycetes. Canadian Journal of Botany 68(12): 2531-2536. DOI: 10.1139/b90-318

Popov E.S., Kovalenko A.E., Gapienko O.S., Kolmakov P.Yu., Melnik V.A., Morozova O.V., Kotkova V.M., Yurchenko E.O., Bondartseva M.A., Belomesyatseva D.M., Shaporova Ya.A., Shabashova T.G., Zmitrovich I.V., Shabunin D.A. 2013. Mycobiota of the Belarus-
Valday Lakeland. Moscow; St. Petersburg: Moscow: KMK Scientific Press Ltd. 399 p. [In Russian]

Pradeep C.K., Justo A., Vrinda K.B., Shibu V.P. 2012. Two new species of Pluteus (Pluteaceae, Agaricales) from India and additional observations on Pluteus chrysaegis. Mycological Progress 11(4): 869-878. DOI: 10.1007/s11557-011-0801-y

Roberts P. 1999. Clavarioid Fungi from Korup National Park, Cameroon. Kew Bulletin 54(3): 517-539. DOI: $10.2307 / 4110853$

Sennikov A.N. 2005. Phytogeography of Northwest Russia (Saint-Petersburg, Pskov and Novgorod regions). Transactions of KarRC RAS 7: 206-243. [In Russian]

Singer R. 1938. Notes sur quelques Basidiomycètes. IVe Série. Revue de Mycologie 3(4): 187-199.

Spirin V., Malysheva V., Trichies G., Savchenko A., Põldmaa K., Nordén J., Miettinen O., Larsson K.-H. 2018. A preliminary overview of the corticioid Atractiellomycetes (Pucciniomycotina, Basidiomycetes). Fungal Systematics and Evolution 2(1): 311-340. DOI: 10.3114/fuse.2018.02.09

Tejklová T. 2018. Houby bohdanečského lázeňského parku a okolí (východní Čechy). Acta Musei Reginaehradecensis. Series A: Scientiae Naturales 37: 19-46.

Tejklová T., Zíbarová L. 2018. A contribution to the knowledge of lignicolous fungi of Podunajská nížina Lowland (Slovakia). Catathelasma 19: 5-77.

Telleria M.T., Dueñas M., Melo I., Salcedo I., Cardoso J., Fernández-López J., Martín M.P. 2016. Corticioid fungi (Basidiomycota) from the Biosphere Reserve of Arganeraie, Morocco: a preliminary survey. Nova Hedwigia 103(1-2): 193-210. DOI: 10.1127/nova_hedwigia/2016/0345

Vasilyeva L.N. 1973. Agaric pileated fungus (Order Agaricales) in the Primorsky Krai. Leningrad: Nauka. 331 p. [In Russian]

Vašutová M., Dvořák D., Beran M. 2013. Rare macromycetes from raised bogs in the Hrubý Jeseník Mts. (Czech Republic). Czech Mycology 65(1): 45-67. DOI: 10.33585/ cmy. 65104

Vetkin Yu.E., Geltman D.V., Litvinova E.M., Konechnaya G.Yu., Mishchenko A.L. (Eds.). 2015. Red Data Book of the Novgorod region. St. Petersburg: Diton. 480 p. [In Russian]

Walleyn R., Vandeven E. (Eds.). 2006. Standaardlijst van Basidiomycota en Myxomycota van Vlaanderen en het Brussels Gewest. Rapport INBO.R.2006.27. Brussel: Instituut voor Natuur- en Bosonderzoek. 140 p.

Wojewoda W. 1977. Grzyby (Mycota). T. 8. Podstawczaki (Basidiomycetes). Trzesakowe (Tremellales). Uszakowe (Auriculariales). Czerwcogrzybowe (Septobasidiales). Flora Polska. Rośliny zarodnikowe Polski i ziem ościennych.Warszawa; Kraków: Państwowe Wydawnictwo Naukowe. 336 p.

Zmitrovich I.V., Stolyarskaya M.V., Kalinovskaya N.I., Popov E.S., Myasnikov A.G., Morozova O.V., Volobuev S.V., Bolshakov S.Yu., Svetasheva T.Yu., Bondartseva M.A., Kovalenko A.E. 2015. Macromycetes of the NizhneSvirsky State Nature Reserve (annotated checklist). St. Petersburg: Svoyo izdatelstvo. 185 p. [In Russian] 


\title{
НОВЫЕ ДЛЯ ПСКОВСКОЙ ОБЛАСТИ ВИДЫ БАЗИДИОМИЦЕТОВ ИЗ ПОЛИСТОВСКОГО ЗАПОВЕДНИКА (РОССИЯ)
}

\author{
Л. Б. Калинина ${ }^{1, *}$, С. Ю. Большаков ${ }^{1}$, Т. М. Бульонкова ${ }^{2}$ \\ ${ }^{1}$ Ботанический институт им. В.Л. Комарова РАН, Россия \\ ${ }^{2}$ Институт систем информатики им. А.П. Ершова СО РАН, Россия \\ *e-mail:lkalinina@binran.ru
}

\begin{abstract}
До начала настоящих исследований в Псковской области было известно 918 видов базидиомицетов, включая 512 таксона, зарегистрированных в национальном парке «Себежский». Инвентаризация грибов является важной частью оценки биоразнообразия. Подобные исследования не теряют своей актуальности в связи с постоянно возрастающим объемом знаний об этой обширной группе организмов, обусловленных как новыми находками, так и успехами молекулярно-генетических исследований. В 2019 г. мы исследовали грибы различных растительных сообществ государственного природного заповедника «Полистовский», а также его охранной зоны на девяти маршрутах. В результате было выявлено 74 новых для Псковской области вида. Шесть из них (Galerina hybrida, Gymnopus erythropus, Lepiota boudieri, Pluteus velutinus, Rugosomyces obscurissimus и Simocybe haustellaris) оказались новыми для Северо-запада Европейской России и четыре (Achroomyces effusus, Botryobasidium stigmatisporum, Galerina caulocystidiata, and Pseudobaeospora celluloderma) - новыми для России. Виды, новые для Северо-запада России, снабжены краткими примечаниями. Для видов, впервые найденных в России, приведены описания изученных образцов, рисунки микроструктур, а также обсуждается их распространение, известные местообитания, близкие виды, и современное состояние данных. Также отмечены два вида, заслуживающие внимания. Это Hemistropahria albocrenulata, находящийся под охраной в Финляндии, Ленинградской и Новгородской областях, и Helicogloea compressa, находка которого является второй на территории России (первое упоминание относится к территории г. Санкт-Петербург). Несмотря на то, что новые данные существенно расширяют знания о базидиомицетах государственного природного заповедника «Полистовский», они недостаточны для полноценного анализа структуры микобиоты.
\end{abstract}

Ключевые слова: Achroomyces effusus, Botryobasidium stigmatisporum, Galerina caulocystidiata, Pseudobaeospora celluloderma, Полистово-Ловатская болотная система, Северо-запад Европейской России 